\title{
Visitas domiciliares pela equipe de Saúde da Família: reflexões para um olhar ampliado do profissional
}

Home Visits by the Family Health Team: thoughts about the need for a broader professional view

Artur Oliveira Mendes* Fernanda Araújo de Oliveira**

\section{Resumo}

As visitas domiciliares assumem papel fundamental na organização do trabalho das equipes do Programa de Saúde da Família (PSF). Contudo, romper com o paradigma biomédico exige uma vigilância nem sempre fácil ou simples, com o objetivo de ampliar o olhar do profissional. Pensando em resolver essa questão, a Equipe Laranja do Centro de Saúde Jardim Montanhês desenvolveu ficha de visita domiciliar, apresentada neste artigo, visando facilitar o planejamento do cuidado do paciente e atentar para questões que fujam à simples intervenção sobre o corpo doente.

\begin{abstract}
Home visits play an essential role in the work of the Family Health Teams. However, breaking the biomedical model and gaining a more comprehensive view of the patients' needs is not always easy or simple. In an attempt to solve this question, the Orange Team of the Health Center Jardim Montanhês created a home visit record form, presented in this paper. This form is aimed at providing information necessary for planning the patient's care and allows taking knowledge of questions that reach beyond the simple treatment of the diseased body.
\end{abstract}

Palavras-chave: Recursos Humanos em Saúde;

Key Words: Health Manpower; Home Visit;

Visita Domiciliar; Humanização da Assistência.

Humanization of Assistance.

\footnotetext{
* Médico, Equipe Laranja, Centro de Saúde Jardim Montanhês, da Secretaria Municipal de Saúde de Belo Horizonte, Prefeitura Municipal de Belo Horizonte, Belo Horizonte, Minas Gerais, Brasil.

** Enfermeira, Equipe Laranja, Centro de Saúde Jardim Montanhês, da Secretaria Municipal de Saúde de Belo Horizonte, Prefeitura Municipal de Belo Horizonte, Belo Horizonte, Minas Gerais, Brasil.
} 


\section{Introdução}

Nos dizeres de Jacquard ${ }^{1}$, a sociedade de hoje não vive apenas uma crise, mas uma mutação irreversível. As mudanças em processo, em todos os campos, não são simples distúrbios que, passados, iriam conduzir-nos ao estado anterior. Sobre a superfície deste planeta, a humanidade encontra-se em um tal questionar de posturas e verdades, que a impressão é a de que vivemos um momento de revoluções, e os saberes da Academia, antes absolutos, dão agora espaço a contra-saberes, formatados em novos contextos, sob novos paradigmas ${ }^{2}$.

As ciências da saúde não poderiam fugir deste processo. O hospital, antes tomado como grande centro do conhecimento sanitário, hoje vem cedendo lugar para novos cenários de prática e construção do conhecimento ${ }^{3}$, estimulantes de um novo processo de formação profissional adequado à era em que passamos a viver. $\mathrm{O}$ trabalhador da área de saúde já não pode se contentar com as informações das consultas, sempre em ambiente controlado, se deseja compreender seu paciente. As interfaces culturais de um caso, por exemplo, dificilmente são explicitadas no consultório.

Assumindo a complexidade que envolve a definição e os cuidados com o estado de saúde em tempos de pósmodernidade, a atenção dada ao ambiente e à teia de relações que o paciente estabelece quando necessitado de cuidados especiais tem na visita domiciliar um importante instrumento para compreensão dos fenômenos e vicissitudes que o "estar doente" suscitam em um espaço definido.

Com o advento do Programa Saúde da Família (PSF) no Brasil, as visitas domiciliares aparecem como uma das principais diretrizes da estratégia, seja pela possibilidade de se entrar no ambiente familiar e conhecer melhor esta realidade (e assim estabelecer planos de ações pertinentes àquele cenário), seja porque uma série de pacientes antes "esquecidos" pelo sistema de saúde devido às suas impossibilidades de locomoção - como vítimas de acidente vascular cerebral (AVC), paraplégicos, deficientes mentais que se recusam a deixar o domicílio, dentre outros casos -, hoje, podem ter contemplado seu direito ao cuidado e ao atendimento.
Contudo, por mais que a proposta se apresente como algo inovador, o simples conhecimento de casos novos não garante a compreensão humana dos problemas enfrentados. A compreensão, como defende Morin ${ }^{4}$, sempre necessita de uma disposição subjetiva. Torna-se necessário um treino do olhar do profissional, nem sempre atento ou disposto a este cuidado ${ }^{5}$. Feuerwerker ${ }^{6}$ lembra, ainda, que mesmo a compreensão das condições de vida, situações socioeconômicas ou da moradia que interferem no processo saúde-doença não bastam para solução dos mesmos se não pudermos nos empenhar na busca de respostas mais potentes para as questões levantadas. A falta de sistematização das visitas, portanto, contribui para desperdício das possibilidades que essa atividade guarda, tornando-se a visita domiciliar, na maioria das vezes, mero espelho da consulta médica e de enfermagem. Este é o produto das reflexões da Equipe Laranja do Programa de Saúde da Família em Belo Horizonte, estabelecida no Centro de Saúde Jardim Montanhês. A proposta abarca, ainda, sugestão de modelo de ficha própria, visando assim à organização das visitas domiciliares e à direção de intervenções.

\section{Justificativa}

O PSF vem cada vez mais se tornando a principal porta de entrada do usuário no sistema de saúde. A demanda crescente nesta fase de expansão do projeto (o número de equipes em atividade no momento é ainda pequeno para atender a totalidade da população) tem sufocado o trabalho dos profissionais de saúde e dificultado o planejamento local das atividades e do cuidado. A responsabilidade sanitária por uma área e o controle e a organização das atividades dão lugar ao atendimento de casos agudos e manutenção de receitas de quadros leves dos diversos agravos, o que contribui para o desgaste dos trabalhadores, que, impossibilitados de enxergar para além das atividades diárias, não vislumbram resultados de seu trabalho e, por vezes, abandonam o PSF ou se entregam à depressão, à desesperança ou ao cinismo (a conhecida síndrome do Burn Out).

Sistematizar os instrumentos de atuação do PSF urge enquanto necessidade política e técnica para o sucesso 
da estratégia. Organizar as visitas domiciliares permitiria otimizar o tempo das equipes, já tão escasso no atual contexto, e definir parâmetros para o acompanhamento da evolução dos casos e consideração sistemática dos aspectos culturais e comunitários envolvidos.

\section{Discussão}

A proposta deste artigo, fruto das reflexões da Equipe Laranja, é a sistematização da visita domiciliar com vias a orientar o plano de cuidado do paciente a partir da compreensão não apenas de sua doença, mas de sua condição enquanto ser humano condicionado e condicionante de um ambiente dado.

Coelho $^{7}$ inova ao discutir a necessidade de priorização de visitas para determinados pacientes considerados em situação de risco. Contudo, não foi possível, nos trabalhos da Equipe Laranja, estabelecer com clareza a divisão que o citado autor propõe ao classificar as visitas em "visita fim", com objetivos focais e "visita meio", voltada para abordagem estratégica. Estiveram, antes, mescladas as características de uma e outra categoria, quando, a partir de uma "visita fim" a um paciente priorizado, como um acamado, pôde-se estabelecer séries de encontros no domicílio para envolvimento da família e traçar metas para a organização do cuidado, com vias à prevenção de agravos e promoção da saúde, quando, então visitas "fim" e "meio" se confundiam, já que o foco sempre esteve sobre um determinado morador, tido como paciente prioritário pela equipe, mesmo quando eram traçadas estratégias envolvendo outros sujeitos. A terminologia, contudo, representa passo importante para objetivação das visitas ao estabelecer que, antes da mesma, é preciso ter em mente um plano, o que também é lembrado no Manual de Assistência Domiciliar na Atenção Primária à Saúde ${ }^{8}$.

Considerando a consulta sob o ponto de vista estritamente biomédico, o trabalho na visita domiciliar ("visita fim”) não difere muito do que pode ser realizado na unidade de saúde, como, por exemplo: controle de pressão arterial (PA) e avaliação de escaras. A riqueza dessa atividade só pode ser revelada se o profissional que executa este trabalho puder enxergar não somente um corpo a ser cuidado, mas um ser humano intrinsecamente ligado ao seu ambiente, influenciandoo e sendo influenciado por ele.

Para perceber os detalhes do mundo da vida é necessário treino e o reconhecimento de quais são os aspectos do território domiciliar que podem influenciar na clínica e no cuidado com a pessoa em estado de vulnerabilidade que se apresenta como foco da visita. A vida que se encontra sob cuidado conta com laços familiares e comunitários que permeiam suas crenças culturais sobre o seu estado atual e que precisam ser consideradas para o sucesso na instituição de um plano terapêutico.

A discussão organizada pelos autores, a ser apresentada sob a forma de explicação dos tópicos do modelo da ficha de visita domiciliar, a seguir, trata da possibilidade de vislumbrar para além da simples consulta ou do teatral aperto de mãos, troca de afagos e lanches. A visita deve ter um caráter profissional, não social, como lembrado por Savassi et. al. ${ }^{9}$, para guiar a atenção a um espaço privilegiado de percepção de aspectos da vida do paciente, os quais não aparecem durante conversas na unidade de saúde. Cunha ${ }^{10}$ aborda essas questões ao discutir a elaboração de Projetos Terapêuticos Singulares (PTS), termo cunhado para sinalizar a importância dada ao indivíduo e seu contexto na organização de um plano de trabalho para a equipe de saúde.

Segue-se a explicação dos pontos que deveriam ser observados durante a visita domiciliar e reflexões pertinentes para organização de PTS, de acordo com o modelo apresentado de ficha (figuras 1 e 2).

Paciente-alvo: mesmo considerando a atenção que deve ser prestada a toda a família, não há sentido prático na realização de pequenas consultas a todos os membros de uma moradia. A demanda excessiva à qual as equipes estão submetidas torna o tempo um artigo precioso que precisa ser otimizado. Portanto, o paciente-alvo de uma visita, sob o qual se dará o foco da investigação em progresso, é, quase sempre, uma pessoa idosa. Trata-se, principalmente, de pessoa incapaz de se deslocar até a unidade de saúde, seja por dificuldades de deambulação (acidentados), seja por questões de ordem psicológica (determinados pacientes com quadro 
de esquizofrenia) ou social (caso de alguns cuidadores, que não podem deixar a pessoa sob sua responsabilidade sozinha) e ambiental (como no caso de pacientes idosos que se movimentam dentro de casa, mas moram em regiões de acesso difícil e que exigiria melhor desempenho físico para ultrapassar barreiras como, por exemplo, escadarias). É preciso, neste item, desenvolver um histórico que defina o caráter da dificuldade a qual justifica a visita e resgatar quando, e sob que condições, o paciente foi, pela última vez, atendido em um serviço de saúde. É necessário também entender qual o grau de dependência do paciente para atividades de vida diária (AVDs), tais como higiene pessoal, e suas implicações na elaboração de um plano de cuidado. Neste espaço, é anotado o endereço do paciente, o número de seu prontuário na unidade e quem é o agente comunitário de saúde (ACS) responsável pela área (este profissional é fundamental para descrição e seguimento do caso).

Cuidador: em geral, há um cuidador, ou alguém que possa ser identificado como tal. É importante entender quem é essa pessoa e qual o seu vínculo com o paciente-alvo (familiar? profissional?) e seus conhecimentos sobre o problema. Pode ser necessário incluir no PTS um plano de capacitação para o cuidador. É preciso, ainda, atentar para o fato de que o cuidador muitas vezes é também pessoa idosa e que precisa também de cuidados. Lahan e Silva ${ }^{11}$ observam que é necessário compreender o cuidador, para “... não exigir além de suas possibilidades, mas não aquém de suas potencialidades". Por vezes existem cuidadores voluntários, treinados, guiados por normas de alguma instituição. O contato com essas pessoas deve ser pautado no contato com a própria instituição (Igreja, Maçonaria etc).

Estrutura familiar: quem se envolve com o cuidado na família? Saber responder a essa pergunta ajuda a definir quem são os potenciais parceiros no tratamento e quais são as pessoas que precisam ser envolvidas para o sucesso do mesmo. Ter conhecimento de quais são as expectativas dos familiares em relação ao caso ajuda a equipe a traçar um plano de metas que leva em conta os desejos ou a desmistificação de crenças dos envolvidos. Qual a qualidade da relação entre os familiares e o paciente? De quais crenças comparti- lham? E entre o cuidador e o paciente? E entre os familiares e o cuidador? Existem amigos da família que fazem visitas ou ajudam no cuidado? Será necessário discutir com algum membro da família em particular sobre o seu grau de envolvimento no caso? Para permitir uma visualização mais direta deste aspecto, é fundamental que aqui possa ser desenhado, ao final, um genograma.

Necessidades para cuidado e tratamento: muitas vezes, as unidades de saúde têm um programa de fornecimento de material para curativo, além do fornecimento de medicamentos, alguns sob regime de compra especial pela secretaria municipal de saúde. É preciso ter clareza desses aspectos para efetuar o planejamento local de necessidades desses insumos.

Medicamentos: é preciso saber como são as condições de estoque. Será que ficam protegidos do alcance de crianças? São organizados de forma clara? Ficam protegidos do calor e da umidade? Quanto ao uso inapropriado... Quem administra? O cuidador sabe aplicar medicamentos, se for o caso? Poderá ser necessária capacitação de cuidadores e familiares, além de orientação específica para o paciente sobre uso, estocagem e efeitos colaterais que influenciem sobremaneira no trabalho, necessitando, por vezes, de reavaliação da prescrição e orientações para o cuidado. Situações como as quedas por uso de benzodiazepínicos e uso de diuréticos (que dificultam, de fato, o trabalho dos cuidadores) precisam ser analisadas. Este tópico não trata de simples lista de medicamentos em uso. Espera-se que esta informação já conste no prontuário do paciente.

Alimentação: quem prepara a comida do paciente? A que horas ele come? Qual a relação desses horários com o uso de medicamentos e outras atividades? Pode ser necessário discutir esses aspectos com a família e avaliar se há necessidade de dieta especial. O paciente tem agenda de horários de alimentação diferente do restante da família? Há de se lembrar que o momento das refeições não deve ser fonte de mais ansiedade e pode ser, ainda, oportunidade de reforçar vínculos e tornar o paciente partícipe da rotina normal da família. Se o paciente depende de ajuda para se alimentar, quem está presente neste momento? Algum familiar? 
Apenas o cuidador?

Ferramentas sociais envolvidas: existem organizações comunitárias envolvidas? Em alguns casos, organizações como a Pastoral da Saúde e grupos de auto-ajuda podem e devem ser comunicados sobre o trabalho da equipe, já que, muitas vezes, obtêm um trânsito fácil na família e adquirem, em muitos contextos, empoderamento para discutir a dinâmica familiar, além de poderem assumir o papel de cuidadores externos ou de ajudantes importantes. Por outro lado, organizações previamente envolvidas no cuidado e sistematicamente desconsideradas pela equipe podem se tornar um problema a mais e fonte de conflitos e disputas desnecessários. Os laços que a família e o paciente estabelecem com sua comunidade precisam ser respeitados para a elaboração de um plano de cuidado que contenha uma visão ampliada de saúde.

Domicílio: a habitação precisa estar preparada para o cuidado, levando-se em conta tanto o quarto do paciente quanto o acesso a outros locais da casa, como o banheiro e a cozinha, de modo a garantir tanto mais independência para o paciente quanto facilitar o trabalho do cuidador. Ambientes mal preparados, seja pela falta de apoios nas paredes, ausência de cuidado com tapetes ou banheiro adaptado, resultam não apenas em dificuldades para o paciente, mas também em fonte de frustração e agravos, por vezes físicos, como dorsalgias, para os cuidadores.

Sabe-se da dificuldade de adaptação de determinados ambientes quando se lida com uma população carente. Contudo, compreender que em médio prazo outros problemas podem ser gerados prepara a equipe para eventualidades e a estimula a usar a imaginação para descobrir alternativas para contornar as dificuldades.

Fontes de prazer do paciente: é preciso lembrar que não se trata do cuidado de um mero corpo e satisfação de necessidades puramente sanitárias. As emoções, como defende Maturana ${ }^{12}$, são fenômenos, também próprios do reino animal, que não podem ser desconsiderados. Um paciente em bom estado geral é o que pode também desfrutar de algumas fontes de prazer. Do que o paciente gosta? Em que atividades o paciente obtém prazer ou com que alimentos ou carinhos? Os familiares se preocupam com isso? Os cuidadores estariam atentos a esse detalhe? Qual a qualidade dos relacionamentos estabelecidos na família e comunidade?

\section{Orientações sobre cuidados emergenciais:} paciente, cuidador e familiares sabem como proceder em caso de situações de emergência, como quedas, intoxicação ou febre? Qual o pacto que a equipe estabelece com a família? Serão realizadas visitas em caráter de urgência, caso se façam necessárias? Existe uma referência para onde encaminhar o paciente? A família tem um plano sobre o que fazer nessas situações? Em alguns casos pode ser necessário que a equipe intervenha, para organização dos envolvidos no cuidado para esses momentos.

Metas: após a avaliação inicial, a equipe precisa traçar um plano de metas e fazer sua avaliação periódica. Além do cuidado estritamente biomédico, o que mais é preciso fazer neste caso? Será necessário traçar um plano de cuidado também para o cuidador? Conversar com mais familiares sobre o seu envolvimento no caso? Elaborar uma visita especialmente para falar a respeito da medicação? Reunir-se com as outras entidades envolvidas no caso? Envolver outro profissional? Qual profissional e como isso seria feito? Dentro de que prazo? Quem é o responsável, na equipe, por essa tarefa? Quando avaliaremos o resultado dessa ação? Qual a periodicidade de visitas necessária? Por quais profissionais? Quais as informações valiosas que o ACS poderá trazer para o restante da equipe no seguimento deste caso e como poderá contribuir para que as metas possam ser atingidas? Este paciente é também atendido por algum serviço privado? Qual é o nível de contato entre esse serviço e os profissionais do setor público? Como estabelecer a comunicação?

Não é preciso traçar uma série de metas de uma só vez. A equipe pode eleger uma e, aos poucos, construir a evolução do caso com novas metas, à medida que os resultados atingidos permitam traçar um novo panorama. No quadro apresentado na ficha sugerida, há de se notar que a anotação de metas vem antes dos problemas. Tal cuidado deve-se à atenção que é necessária para que o plane- 
jamento não se torne mero "tapa-buracos" de uma situação observada. Os problemas devem ser estabelecidos em função dos objetivos pretendidos, e não o contrário. Um problema é, portanto, uma dificuldade para se atingir determinada meta. É preciso, ainda, definir uma estratégia geral e um responsável, na equipe, que se debruce sobre a mesma e fique atento ao prazo.

Visitas posteriores: este anexo deve ser preenchido a cada nova visita, estabelecendo objetivos para a mesma em razão das metas e, ao final, a avaliação dos resultados específicos. Não há limites para o número de visitas, o espaço especificado na ficha apresentada neste artigo é apenas ilustrativo.

Evolução do caso: Quando são traçadas metas, estabelece-se um prazo para avaliar seu cumprimento. Esse tópico deve ser preenchido a cada reavaliação do caso, permitindo traçar um novo panorama sobre o mesmo e definir novas metas. As datas postas à esquerda tratam das datas das reavaliações (estabelecidas no momento de definição da meta em questão).

\section{Considerações finais}

O uso de ficha de visita domiciliar proporcionou melhor organização do trabalho da equipe Laranja. A ficha pode ser preenchida durante primeira visita e completada em discussão com toda a equipe no centro de saúde. Ao final do prazo de avaliação de um certo número de metas, repensar o caso e proceder ao preenchimento de uma nova ficha, já que, provavelmente, estaríamos com um outro contexto, necessitando de outras metas. Pode ser definido também que uma nova ficha deva ser elaborada a cada novo ano, permitindo assim que a equipe organize sua agenda de cuidados para este período.

Alguém da equipe precisa ser responsável pelo seguimento das fichas para que haja garantia de avaliação periódica do plano de metas e cobrança do resultado e desenvolvimento das ações, atribuídas a um determinado profissional, quando de sua elaboração.

A utilização da ficha não substitui o prontuário, nem há a pretensão de que a mesma lhe sirva de folha de rosto. O prontuário continua sendo o espaço de anotação dos dados do paciente durante a consulta que, durante a visita, é realizada. A ficha se presta à organização e ao seguimento do plano terapêutico.

Ainda que sejam feitas críticas ao modelo biomédico, não há aqui tentativa de desconsiderar sua importância. Ao lado do trabalho proposto para as visitas, deverá sempre constar elaboração de um projeto terapêutico que não desconsidere questões do campo biológico do paciente. $\mathrm{O}$ diferencial desta discussão trata da importância que precisa também ser dada ao contexto no qual o paciente está inserido e seus medos e desejos que influenciam na organização do cuidado, inclusive biomédico.

Para o sucesso desta proposta, é necessário que toda a equipe se envolva e disponha de período próprio para discussão dos casos. Infelizmente, não é rotina em algumas equipes o agendamento de reuniões semanais. Sem este espaço, não apenas a proposta apresentada, mas quaisquer tentativas de planejamento no PSF não poderão lograr êxito.

Este artigo não pretendeu resolver todas as questões relacionadas ao tema. Contudo, a ciência e a humanidade avançam em espiral. Velhos temas tornam-se objeto de estudo e novas questões surgem a cada momento. Assim, espera-se que outros autores possam avançar no que foi proposto, e, assim, possamos, profissionais de saúde no Brasil, construir um conhecimento que seja capaz de dar respostas cada vez mais pertinentes às provocações que este novo mundo nos lança.

\section{Referências}

1. Jacquard A. Da angústia à esperança: lições de ecologia humana. Petrópolis (RJ): Vozes; 2004.

2. Pereira WCC. Nas trilhas do trabalho comunitário e social: teoria, método e prática. Belo Horizonte (MG), Petrópolis (RJ): PUC Minas, Vozes; 2001 .

3. Bulcão LG. O ensino médico e os novos cenários de ensinoaprendizagem. Rev Bras Educ Méd. 2004; (1): 61-72.

4. Morin E. O método 6: ética. Porto Alegre (RS): Sulina; 2005. 5. Lown B. A arte perdida de curar. São Paulo: JSN Ed.; 1997. 6. Feurwerker L. Reflexões sobre as experiências de mudança 
Figura 1 - frente da ficha de visita domiciliar

\begin{tabular}{|l|l|}
\hline \multicolumn{2}{|c|}{ FICHA DE VISITA DOMICILIAR } \\
\hline Paciente alvo: & \\
\hline Cuidador: & \\
& Ferramentas sociais envolvidas: \\
\hline Necessidades para o cuidado e tratamento: & \\
& Orientações sobre cuidados emergenciais: \\
& \\
\hline Domicílio: & \\
\hline Fontes de prazer do paciente: & \\
&
\end{tabular}

Figura 2 - verso da ficha de visita domiciliar

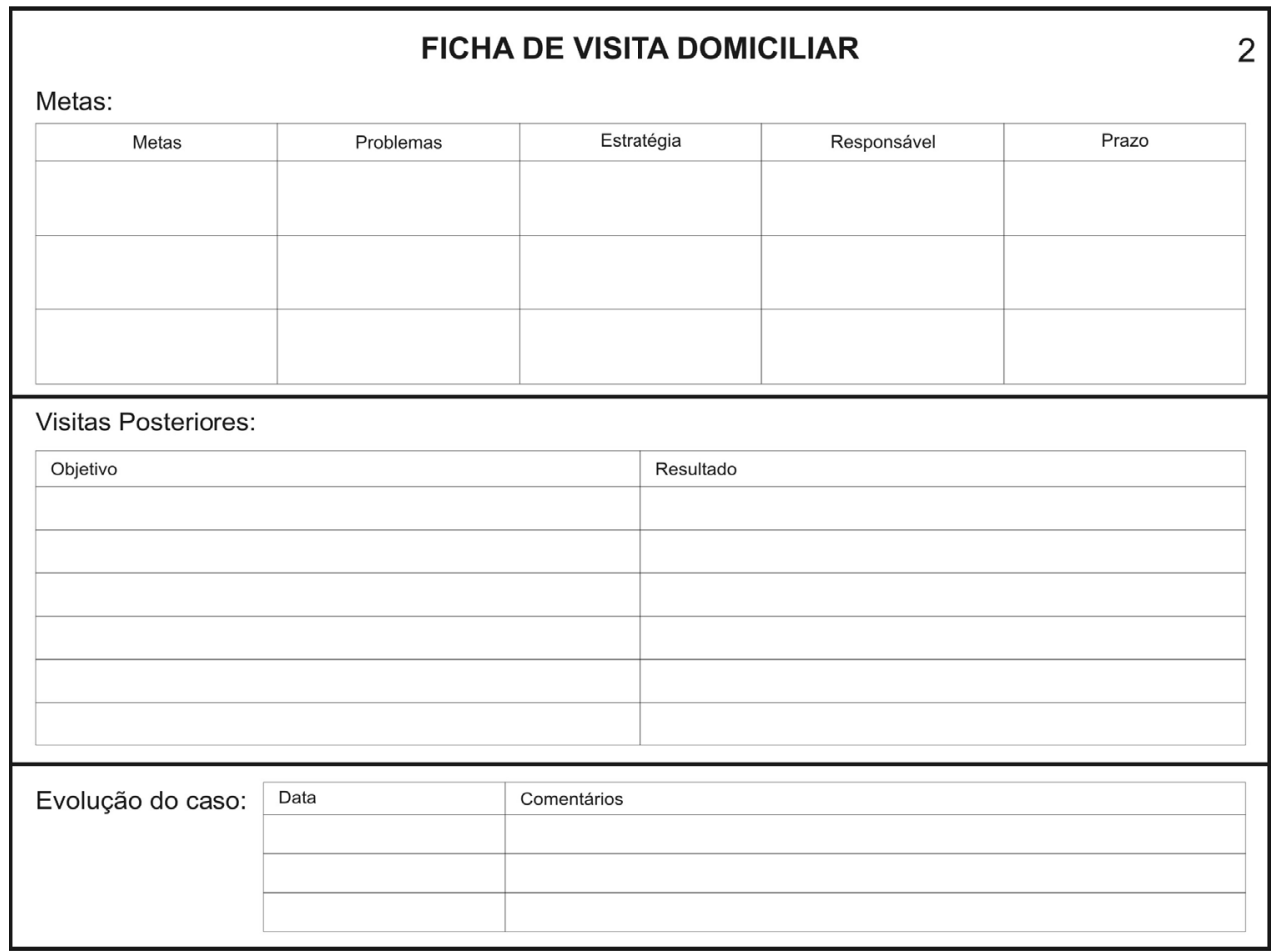


na formação de profissionais de saúde. Olho Mágico. 2003;

(3): 21-26.

7. Coelho FLG; Savassi LCM. Aplicação da escala de risco familiar como instrumento de priorização de visitas domiciliares. Rev Bras Med Família Comun. 2004; (2): 19-26.

8. Brasil. Ministério da Saúde. Grupo Hospitalar Conceição. Manual de assistência domiciliar na atenção primária à saúde. Porto Alegre (RS): Serviço de Saúde Comunitária do Grupo Hospitalar Conceição; 2003.

9. Savassi LCM; Dias MF; Dias MB; Sá MMG, Sá MJ. Relatoria do GESF: Módulo Visita Domiciliar. Grupo de Estudos em Saúde da Família. Belo Horizonte (MG): AMMFC; 2006. Disponível em: . Acesso em: 31/12/2006. 10. Cunha GT. A construção da clínica ampliada na atenção básica. São Paulo: Hucitec; 2005.

11. Lahan CF; Silva LA. O cuidador. In: Jacob Filho Wilson (ed.). Avaliação global do idoso: manual da liga do gamia. São Paulo: Atheneu; 2005.

12. Maturana H. Emoções e linguagem na educação e na política. Belo Horizonte (MG): Editora UFMG; 2002.

\section{Endereço para correspondência:}

Artur Oliveira Mendes

Centro de Saúde Jardim Montanhês

Rua Leopoldo Pereira, 407 - Bairro Jardim Montanhês

Belo Horizonte MG - CEP: 30750-140

\section{Endereço Eletrônico}

gorutubano@yahoo.com.br 